\title{
O MANTO DE ARTHUR BISPO
}

\section{THE MANTLE OF ARTHUR BISPO}

\author{
Marco Lucchesi ${ }^{l}$
}

RESUMO: Este texto é o discurso de posse na presidência da Academia Brasileira de Letras, proferido em 14 de dezembro de 2017, no qual o passado e o presente são revisitados, na voz de autores e textos, e o futuro se projeta em desejos e sonhos. O sonho do Brasil como um livro em construção. Um livro de muitos autores, com muitos ângulos, espelhado, onde cada qual se reconheça em suas páginas, como fizeram Lima Barreto e Machado de Assis. Como se fora o manto de apresentação de Arthur Bispo do Rosário. Uma cartografia total. A memória de tudo, em todos.

PALAVRAS-CHAVE: Literatura. Academia Brasileira de Letras.

\begin{abstract}
This text is the inaugural speech of the president of the Brazilian Academy of Letters, given on December 14, 2017, in which the past and present are revisited in the voices of authors and texts and the future is projected in desires and dreams. The dream for Brazil is that of a book under construction. A book of many authors, with many angles, mirrored, where each individual can be recognized in its pages, as Lima Barreto and Machado de Assis did. As if it were the mantle of Arthur Bispo do Rosário. A total cartography. A memory of all, in all.
\end{abstract}

KEYWORDS: Literature. Brazilian Academy of Letters.

\footnotetext{
${ }^{1}$ Professor titular de Literatura Comparada (Ciência da Literatura / UFRJ)/CNPq, professor convidado da FioCruz, Presidente da Academia Brasileira de Letras. Graduado em História pela UFF, mestrado e doutorado em Letras (Ciência da Literatura - UFRJ) e pós-doutorado na Universidade de Köln (Alemanha). Rio de Janeiro, Brasil. E-mail: marcolucchesi2018@gmail.com.
} 
A liturgia de posse da nova diretoria traduz um rito de passagem, pressupõe a liturgia de sua identidade, revela a memória transitiva da Casa.

Um modo sazonal aquece e restitui os laços de uma comunidade de destino, como a nossa, permanente e provisória. Cada um de nós é um traço de união entre o passado e o futuro, lugar-tenente daqueles que partiram e de quantos vão chegar.

O tempo que nos rege parece dispor de uma ideia circular, dialética da imagem e do espelho, memória que corre do passado para a incerta espessura do presente, essa, que nos fere e atravessa, irreparável, quando invocamos uma parcela de futuro, cujo rosto mal podemos vislumbrar, a nós fraterno, é o que se espera, semelhante e desigual.

Se a memória é um repertório de alusão e esquecimento, o futuro não passa de uma realidade expandida e de uma inesgotável fonte de heterônimos.

Essa memória coletiva, esse pantempo de T. S. Eliot, em cujas redes fomos apanhados, não coleciona pálidos espectros, mas obras e autores que traduzem parte do que somos, sinal de nossa alteridade, métrica de sonhos esparsos, fragmentos de luz.

Nessa janela de tempo, e a partir desta tribuna, vejo Machado de Assis, rodeado de amigos, na Livraria Garnier, cidade inabordável, órfã do Morro do Castelo e da igreja de São Pedro dos Clérigos, enquanto dorme Quincas Borba nas escadarias da igreja de São Francisco. Ouço, ao mesmo tempo, como num rádio de ondas curtas, além dos rumores da propagação, a voz da presidência desta Casa em 2090, a quem envio saudações cordiais, como quem lança uma garrafa em águas turvas e cristalinas do espaço-tempo. 
Entre passadas gentes e futuras, leio a adaptação de Ferreira Gullar do famoso poema de Walt Whitman, "Full of Life", contornando a falha geológica entre as gerações, ausência habitada por cardumes de livros, palavras, afeições:

\author{
A ti que ainda não nasceste, dirijo este canto, \\ quando leias isto, eu, que agora sou visível, terei \\ me tornado invisivel, \\ enquanto tu serás consistente e visível, e darás \\ realidade a meus poemas, voltando-te para mim, \\ imaginando como seria bom se eu pudesse estar \\ contigo e ser teu camarada: \\ faz de conta que eu estou contigo. \\ (E não o duvides muito, porque eu estou aí nesse momento).
}

Estamos juntos, não duvidemos, aqui, nessa tarde obstinada, e nesta Casa, onde afinamos nossa língua e nossos instrumentos de sentir, com olhos de ressaca e de neblina, em Machado, passando por Whitman, e radicados no sertão de Guimarães Rosa.

Habitamos o coração do presente, a quem pagamos o tributo e a moldura de nosso horizonte. Importa distinguir o abismo da memória entre as madeleines de Proust e um eterno chá das quintas, como o roteiro de "O Anjo exterminador" de Buñuel, de cujo cenário já não podemos sair. Anjo apenas, torto à maneira de Drummond, longe de perpetrar algum tipo de extermínio.

Se assim não fosse e se a tanto se limitasse a Casa de Machado, seríamos devorados pela segunda lei da termodinânica, desfazendo de uma vez por todas, nossa vocação ecumênica, os cuidados com a língua e a literatura, cujo processo não para de crescer, e exige um olhar intenso e vário, poroso e aberto sobre nossa terra, o país e o mundo, no imenso fractal de memórias na web.

Não queremos uma torre de marfim, uma linguagem sacra e muito menos a reclusão dentro de nossas possíveis e agudas feridas narcísicas. Não apostamos num regime de pensamento único, nem esconjuramos tampouco a promoção da diversidade.

Brilha como um farol o poder simbólico da cadeira 41, onde se abriga o maior número de acadêmicos, ao longo de sua história, formando um universo paralelo de alto valor. Lembramos o mantra de Joaquim Nabuco: não somos os quarenta, somos quarenta.

Eis a realidade que impele a compreender a alta responsabilidade de uma Casa desenhada para o Brasil, autônoma, independente, e, é bom que se diga, autofinanciada, e ao mesmo tempo, sem contradição no adjetivo, propriedade do povo brasileiro, forjada igualmente no imaginário da nação, herança dadivosa da qual, acadêmicos ou não, somos todos herdeiros, no quintal de Bentinho e Capitu, nas últimas páginas de Euclides, no laboratório de Moacir Scliar.

Donde o imperativo de repensar escala e proporção, a história do país e da Academia, entrelaçadas, quase indistintas, ocupados como vamos na construção de um feixe de compromissos de liberdade e releituras onde prospere o diálogo e a saudável diferença que nos une, abertos aos desafios de nosso tempo. 
Uma Academia que não abdique de seus estatutos, olhando para o Brasil como um todo, não limitada apenas a uma parte, eixo ou região, promovendo ações sociais compatíveis com seu regimento, sem jamais perder uma visão mais planetária.

Tantos os desafios atuais, da ameaça aos direitos humanos à autonomia da universidade. A Academia não faz política, mas defende a cultura. Toma as distâncias devidas, mas não se nega às imersões necessárias.

Confesso um certo grau de perplexidade, misto de surpresa e emoção que me atinge. Se jamais pensei integrar esse alto colegiado, bem menos cogitei a hipótese, ousada e remota, de viver a cerimônia dentro da qual ora me vejo implicado, sem rota de fuga ou saída de emergência.

Houve decerto mais fortuna que virtù, um grão de temeridade e simpatia por parte da Casa. Perdi o direito de errar, pois a quem muito se concede bem mais se exige.

Só me resta o zelo diuturno e obstinado. A entrega cheia de adesão. E, por fim, um pouco de imaginação e outro tanto da insônia que me circunda feroz, desde que assumi a tesouraria. Não sei ao certo se devo culpar ou agradecer a votação unânime.

Quis sempre, apenas e bastante, a literatura como forma de ler o mundo e aplacar minhas demandas de alteridade, como quem abre, nos livros e semblantes, uma janela para o novo: translúcidos seus olhos e as figuras no horizonte. E, no entanto, eis-me aqui diante desse incontornável desafio. O solitário deve tomar-se mais solidário, cônscio do capital simbólico e da complexa administração. Serei o presidente de todos, centrado na paz e na harmonia.

Sucedo a um presidente de múltiplas virtudes: probo, dedicado, inteligente, com uma década de serviços prestados à instituição.

A presidência de Domício Proença Filho será lembrada pelos valores dominantes da isonomia, transparência e sensibilidade pelos mais vulneráveis. Para não falar do projeto do Centro de Estudos e Pesquisa da Língua Portuguesa, Cepelp.

Raramente se encontram num só indivíduo o equilíbrio notável entre leveza e gravidade. $\mathrm{O}$ presidente prevaleceu sobre o escritor a maior parte do tempo, a tudo e a todos antepondo a Academia, convicto de que a Casa nos transcende e exige todos os cuidados.

Permito-me cumprimentar, de coração aberto e andarilho, a Acadêmica Nélida Piñon, cujo estímulo e presença marcaram a travessia. Uma república vivida em sonho é também, querida Nélida, si licet, um pródigo sinal de utopia latente.

Precisamos de um sinal de esperança. $\mathrm{O}$ ano vindouro prolonga os desafios atuais, em meio à crise que se abate feroz sobre o mercado imobiliário do Rio de Janeiro, cidade fascinante que os desgovernos recentes procuraram devastar.

Mas a cidade e o seu povo resistem bravamente.

O ano de 2018 será o mais intenso na história da Casa. Faz-se urgente trabalhar com firmeza e equilíbrio, sem arrogância e precipitação, com os cuidados sociais, longe de atitudes messiânicas ou apocalípticas. 
O sim que pronuncio nesta tarde como presidente circunscreve-se ao volume de soluções que precisamos construir juntos, com olhos abertos, generosos.

Não posso deixar de ser quem sou. Seguirei visitando as prisões. Não deixarei de ir às comunidades, ajudando a formar bibliotecas, com igual serenidade e destemor.

Em nome de meu avô paterno, que sobreviveu ao campo de concentração de Mauthausen, e do primo de minha mãe, falecido de inanição em outra parte do Terceiro Reich. Tenho um dever moral. Amo esta cidade, que agoniza em muitas regiões, com novas modalidades de extermínio, lá onde não chega o estado.

Antes de concluir, quero revelar um sonho, de olhos abertos.

Penso o Brasil como um livro em construção, e desde um ponto zero, talvez, em cujas folhas segue o desejo de inclusão de muitas vozes, num concerto polifônico, estridente, a princípio, e fora do compasso, fruto de uma espera infinita pelo fim da desigualdade. Continuemos juntos. A tolerância é um bem que se constrói em rede, em torno de estatutos de emancipação.

Sonho um livro de muitas páginas, voltado a uma vasta vocação republicana, pela qual lutaram tantos acadêmicos. Não sei dizer onde começam e terminam os grafites urbanos, os poemas que redimem a crispação de nossas ruas e de nossas casas, os desenhos rupestres da Serra da Capivara, a liberdade esboçada nas paredes dos presídios, a leitura do mundo das crianças do asfalto e da favela, as terras quilombolas e as nações indígenas, com suas quase 300 línguas praticadas ainda hoje. Um livro sem escravos análogos e digitais.

Um livro de muitos autores, com muitos ângulos, espelhado, onde cada qual se reconheça em suas páginas, como fizeram Lima Barreto e Machado de Assis. Como se fora o manto de apresentação de Arthur Bispo do Rosário. Uma cartografia total. A memória de tudo, em todos.

A Academia, diante disso, é um grafite luminoso, abrindo alguns capítulos, sobre muros que se abatem e passagens para o diálogo, sinal de paz, breve tatuagem no corpo do país, soma de vozes, concerto inacabado, saudoso do futuro.

Recebido em 21/12/2017

Aceito em 30/12/2017 